\title{
Spatiotemporal Dynamics of Perfusion and Oximetry during Ictal Discharges in the Rat Neocortex
}

\author{
Mingrui Zhao, Hongtao Ma, Minah Suh, and Theodore H. Schwartz \\ Department of Neurological Surgery, Weill Medical College of Cornell University, New York Presbyterian Hospital, New York, New York 10021
}

Epileptic events elicit a large focal increase in cerebral blood flow $(\mathrm{CBF})$ to perfuse metabolically active neurons in the focus. Conflicting data exists, however, on whether hemoglobin saturation increases or decreases in the focus and surrounding cortex, and whether CBF increases globally or is decreased in adjacent areas. How these hemodynamic events correlate with actual changes in tissue oxygenation is also not known. Using laser Doppler flowmetry, oxygen microsensors and intrinsic optical imaging spectroscopy, we demonstrate that the dip in hemoglobin in the focus correlates with a profound but temporary decrease in tissue oxygenation despite a large increase in $\mathrm{CBF}$. Furthermore, $\mathrm{CBF}$ simultaneously decreases in the cortex immediately adjacent to the focus. These events are then replaced with a longer duration, less focal increase in $\mathrm{CBF}$, cerebral blood volume, and hyperoxygenation, the duration of which correlates with the duration of the seizure. These findings raise the question of whether transient focal hypoxia and vascular steal might contribute to progressive deleterious effects of chronic epilepsy on the adult and developing brain. Possible mechanisms based on recent astrocytebased models of neurovascular coupling are discussed.

\section{Introduction}

Neuroimaging techniques such as functional magnetic resonance imaging (fMRI) and intrinsic optical imaging (IOS) indirectly measure neuronal activity based on changes in cerebral blood flow (CBF), cerebral blood volume (CBV) and hemoglobin oxygenation. Interpreting these hemodynamic-based measurements is complex and critically dependent on a comprehensive understanding of the competing effects of increased metabolic demand for oxygen and increased delivery of oxygenated hemoglobin, otherwise known as neurovascular coupling (Logothetis and Wandell, 2004; Raichle and Mintun, 2006). While the majority of investigations into mechanisms of neurovascular coupling have been performed during normal somatosensory processing, very few studies have examined neurovascular coupling during pathological states such as epilepsy (Girouard and Iadecola, 2006). Epilepsy is an abnormal physiologic state which, unlike normal somatosensory processing, places supranormal demands on the brain's autoregulatory mechanisms due to the enormous increase in neuronal metabolism of oxygen $\left(\mathrm{CMRO}_{2}\right)$ following both interictal and ictal events (Folbergrová et al., 1981). Hence, neurovascular coupling mechanisms that apply during normal cortical processing may not be relevant to the epileptic brain. Likewise, epileptic events are dynamic and spread inhomogenously across

Received Sept. 29, 2008; revised Jan. 23, 2009; accepted Jan. 24, 2009.

This work was supported by National Institute of Neurological Disorders and Stroke Grant R01 NS49482 (T.H.S.). We thank Dr. Costantino ladecola for help with the manuscript, Dr. Laibaik Park for help with laser Doppler flowmetry measurements, and Sadaat Shariff and Andrew Geneslaw for technical assistance.

Correspondence should be addressed to Dr. Mingrui Zhao, Department of Neurological Surgery, Weill Medical College of Cornell University, 525 East 68th Street, Box 99, New York, NY 10065. E-mail: miz2003@med.cornell.edu. M. Suh's present address: Department of Biological Science, Sungkyunkwan University, Suwon, South Korea. D01:10.1523/JNEUROSCI.4667-08.2009

Copyright (C) 2009 Society for Neuroscience $\quad 0270-6474 / 09 / 292814-10 \$ 15.00 / 0$ the cortex on a faster timescale than the indirect hemodynamic signals, which effectively blur this complexity.

Using IOS, our laboratory has recently reported that both interictal and ictal epileptic events elicit a dip in hemoglobin oxygenation that is higher in amplitude and longer in duration than seen during normal somatosensory processing in both animal (Schwartz and Bonhoeffer, 2001; Suh et al., 2005; Bahar et al., 2006) and human brain (Zhao et al., 2007). However, it was unclear if this data arose from an enormous increase in CBV rather than an actual increase in deoxygenated hemoglobin (Hbr) (Buxton et al., 1998). Likewise, spectroscopic imaging was not performed to quantify $\mathrm{Hbr}$ and $\mathrm{CBV}$ and account for light scattering (Sheth et al., 2003). It was also difficult to reconcile a long epileptic-deoxygenation with fMRI studies of epilepsy that show a positive blood oxygen-level dependent (BOLD) signal, consistent with an ictal hyperoxygenation (Aghakhani et al., 2004; Nersesyan et al., 2004a). As fMRI becomes more widely used as a method for clinically localizing seizures in preparation for surgical treatment, an understanding of epileptic neurovascular coupling becomes increasingly important. Another curious phenomenon described in IOS and fMRI studies of epilepsy is the "negative signal," which has been reported from the area surrounding an epileptic focus (Haglund et al., 1992; Schwartz and Bonhoeffer, 2001; Suh et al., 2005). Originally thought to correspond with a ring of neuronal inhibition, the origin of the negative intrinsic signal change is unclear from a hemodynamic perspective, since the IOS studies reporting the negative signal were done either at a single wavelength sensitive only to light scatter or without spectroscopic analysis, and the BOLD signal arises from a combination of hemodynamic events related both to hemoglobin oxygenation and CBV.

To address these outstanding questions, we performed simultaneous IOS spectroscopy and direct tissue measurements of oxygen tension with two oxygen sensitive electrodes, one placed in the focus and one in the adjacent surrounding cortex of an acute 
ictal focus in rat neocortex. Two laser Doppler flowmetry (LDF) probes were also used to directly measure $\mathrm{CBF}$ from the focus and surround to describe the spatiotemporal evolution of the hemodynamic events associated with an ictal event.

\section{Materials and Methods}

Animal preparation. All experimental procedures were approved by the Weill Cornell Medical College Animal Care and Use Committee following National Institutes of Health guidelines. Adult male Sprague Dawley rats $(250-380 \mathrm{~g})$ were initially anesthetized with $2-4 \%$ isoflurane in $70 \%$ $\mathrm{N}_{2}: 30 \% \mathrm{O}_{2}$ by facemask and maintained on $1-3 \%$ isoflurane in $70 \% \mathrm{~N}_{2}$ : $30 \% \mathrm{O}_{2}$. Body temperature was maintained at $37^{\circ} \mathrm{C}$ with a regulated heating blanket (Harvard Apparatus). The heart rate, arterial blood oxygen saturation $\left(\mathrm{SpO}_{2}\right)$, and End-Tidal $\mathrm{CO}_{2}\left(\mathrm{ETCO}_{2}\right)$ were carefully monitored with a SurgiVet V9004 Capnograph (SurgiVet) and were maintained stable at normal values throughout the experiment (heart rate: $250-300$ pulse/min, $\mathrm{pO}_{2}>90 \%, \mathrm{ETCO}_{2} \sim 25-28 \mathrm{mmHg}$ ). An electrocardiogram was recorded between leads attached to the right hindlimb and to the scalp, which was shaved. Animals were placed in a stereotaxic frame. A $\sim 5 \times 8 \mathrm{~mm}$ cranial window was opened over one hemisphere between $\lambda$ and bregma to expose somatosensory cortex and surrounding brain. The dura was carefully removed. A custom chamber was adhered to the skull and filled with silicone oil (viscosity $\sim 30000$ $\mathrm{mPa} . \mathrm{s}$, Sigma) after positioning all electrodes and/or probes.

Epilepsy model and electrophysiology. Ictal discharges were induced by injecting 4-aminopyridine (4-AP, Sigma, $15 \mathrm{~mm}, 0.5 \mu \mathrm{l}$ ) through a singlebarreled glass microelectrode using a Nanoject II injector (Drummond Scientific). A second single-barreled glass microelectrode (impedance, 2-4 $\mathrm{M} \Omega$ ) filled with $0.9 \%$ saline was positioned $<1 \mathrm{~mm}$ from the 4-AP electrode and lowered to a depth of 300 500 $\mu \mathrm{m}$ into the neocortex. Extracellular local field potential (LFP) was amplified and filtered between 0.1 and $500 \mathrm{~Hz}$ using a DAB-S system (World Precision Instruments), and digitized at 1000 $\mathrm{Hz}$ by a CED Power 1401 (Cambridge Electronic Design). Data were recorded by a PC running the Spike2 software (Cambridge Electronic Design).

Laser Doppler flowmetry. Two custom angled stainless steel LDF probes were placed on the cortex simultaneously to avoid large blood vessels (wavelength, $780 \mathrm{~nm}$; fiber separation, $0.25 \mu \mathrm{m}$; Perimed); one as close as possible to the 4-AP electrode (heretofore referred to as the "Focus") and the second at least $2 \mathrm{~mm}$ away in the cortex surrounding the ictal onset zone (heretofore referred to as the "Surround"). LDF provides continuous hemodynamic monitoring of red blood cell velocity and red cell concentration yielding a calculated CBF measure that correlates with traditional methods (Skarphedinsson et al., 1983). CBF was continuously recorded by the PeriFlux System 5000 (Perimed). Data were acquired at $200 \mathrm{~Hz}$ with a $0.05 \mathrm{~s}$ time constant using a CED Power 1401 and Spike2 software (Cambridge Electronic Design). Cross-talk between the two Doppler probes was determined by extinguishing and illuminating one probe at varying the distance away from the second probe while recording the change in light intensity (see supplemental Material, available at www.jneurosci.org).

Tissue oxygenation. Tissue oxygenation was measured with two simultaneous Clark-style polarographic oxygen microsensors, which respond linearly to tissue oxygen concentration changes. The tip of the microsensor is 25 $\mu \mathrm{m}$ in diameter with a $90 \%$ response time of $<0.5 \mathrm{~s}$. The tip measures a sphere of tissue $\sim 60 \mu \mathrm{m}$ in diameter. Calibrations were performed at $37^{\circ} \mathrm{C}$ in saline equilibrated with either bubbling air (atmospheric $\mathrm{pO}_{2}$ ) or $100 \% \mathrm{~N}_{2}$ gas $\left(\right.$ zero $\mathrm{pO}_{2}$ ) before each experiment. The oxygen microelectrodes were inserted $\sim 400 \mu \mathrm{m}$ deep into the neocortex, one located as close as possible to the 4-AP injection site ("Focus") and the other positioned at least $2 \mathrm{~mm}$ away ("Surround"). The signal was measured with a high-impedance picoammeter (PA 2000, Unisense) and recorded to the computer by a CED Power 1401 and Spike2 software (Cambridge Electronic Design). An off-line $0.3 \mathrm{~Hz}$ lowpass filter was used to remove the artifacts caused by spatial displacement (Masamoto et al., 2003; Offenhauser et al., 2005).

Intrinsic optical spectroscopic imaging. The exposed cortical surface was illuminated with white light using a $100 \mathrm{~W}$ halogen lamp with a DC regulated power supply through two fiberoptic light guides. Reflected light from the cortical surface was collected by a $50 \mathrm{~mm}$ camera lens and divided into two separate paths by a beamsplitter. Each light beam passed through a second $50 \mathrm{~mm}$ camera lens and an interference filter tuned to one of two different wavelengths $(570 \pm 10$ or $610 \pm 10 \mathrm{~nm})$. These wavelengths were chosen because $570 \mathrm{~nm}$ is an isosbestic wavelength of hemoglobin, meaning that hemoglobin absorbs light equally well in the oxygenated and deoxygenated state and provides a direct measure of total hemoglobin (Hbt). Hbt is equivalent to cerebral blood volume (CBV) if the hematocrit remains constant, and CBV is proportional to CBF (Sheth et al., 2004a). At $610 \mathrm{~nm}$, however, deoxygenated hemoglobin (Hbr) absorbs light more strongly than oxygenated hemoglobin $\left(\mathrm{HbO}_{2}\right)$, and it is possible to directly quantify both $\mathrm{Hbr}$ and $\mathrm{Hbt}$ with the appropriate calculation (see below) (Frostig et al., 1990; Sheth et al., 2004b) Pixels were binned $2 \times 2(21 \mu \mathrm{m} /$ pixel $)$ and collected by two charge-coupled device cameras, and images were acquired at a frame-rate of $10 \mathrm{~Hz}(\mathrm{Im}-$ ager 3001, Optical Imaging). The camera was focused $\sim 500 \mu \mathrm{m}$ below the cortical surface. A floating bench (Newport) was used to minimize motion artifacts.

Optical imaging could be performed simultaneously with oxygen microelectrode recording but not simultaneously with the Doppler measurements on account of the size of the Doppler probes.

Data analysis. LFP data were acquired simultaneously with either LDF or combined $\mathrm{pO}_{2}$ and IOS to measure the onset-time of the seizure and duration. The offline analysis was performed using custom analysis software written by Matlab (MathWorks). Seizure onset was determined by visual analysis of the EEG from the initial negative deflection of the large spike that preceded all seizures. Since ictal events can have a varying electrographic morphology, we only analyzed those that had no interictal spikes during the $10 \mathrm{~s}$ before the ictal onset and that began with a large population spike followed by a recruiting rhythm to eliminate any confusion regarding the onset of the seizure (see Fig. 1). Termination was determined at the cessation of spike and wave events and the return to baseline, preictal activity. $\mathrm{CBF}$ and tissue $\mathrm{pO}_{2}$ data were converted to percent change $(\Delta)$ from baseline by subtracting then dividing the average baseline value obtained over a $2 \mathrm{~s}$ block of time beginning $2 \mathrm{~s}$ before the onset of the ictal discharge using Equation 1:

$$
V_{\% \Delta \text { baseline }}=\left(V_{\text {raw }}-V_{\text {baseline }}\right) / V_{\text {baseline }} \times 100 \%,
$$

where $V_{\% \Delta \text { baseline }}$ is the final value of $\mathrm{CBF}$ and $\mathrm{pO}_{2}, V_{\text {raw }}$ is the raw value, and $V_{\text {baseline }}$ is the average baseline value.

The magnitude of the response was estimated as the area under the curve above (positive) or below (negative) two SDs from the pre-event baseline.

For the optical signals, a modified form of the Beer-Lambert law was used to calculate $\mathrm{Hbr}, \mathrm{HbO}_{2}$, and $\mathrm{Hbt}$ changes from the $570 \mathrm{~nm}$ and 610 $\mathrm{nm}$ data with pathlength correction (Sato et al., 2002; Sheth et al., 2004b) using Equation 2:

$$
\log \frac{I_{0}^{\lambda}}{I(t)}=\left(\epsilon_{\mathrm{Hbr}}^{\lambda} \times \Delta[\mathrm{Hbr}](t)+\epsilon_{\mathrm{HbO}_{2}}^{\lambda} \times \Delta\left[\mathrm{HbO}_{2}\right](t)\right) \times l^{\lambda}+\Delta S .
$$

$I_{0}$ is the prestimulus intensity, $I(t)$ the measured intensity time course, $\varepsilon$ extinction coefficients, $l$ the pathlength through the tissue, $S$ scattering, $\Delta[\mathrm{Hbr}](t)$ and $\Delta\left[\mathrm{HbO}_{2}\right](t)$ are the time courses of change in absorption, and superscript $\lambda$ indicates wavelength dependency. By measuring $I_{\mathrm{o}}$ and $I(t)$ at two wavelengths and using the known wavelength dependency of the optical pathlength $(\alpha=\varepsilon \times l)$, we determine a pathlength corrected value of $\Delta[\mathrm{Hbr}](t)$ and $\Delta\left[\mathrm{HbO}_{2}\right](t)$.

Functional spectral time courses were reported as relative changes from baseline. Each frame following the onset of each seizure was divided by an average of the 20 frames before the onset. Spatial low-pass filtering was achieved by convolution with a Gaussian kernel ( $\sigma=3$ pixels, $\sim 63$ $\mu \mathrm{m})$. Two region of interest (ROI; $5 \times 5$ pixels) were selected. One was on the ictal focus (adjacent to oxygen microsensor in the focus) and the other was in the ictal surround (adjacent to the second distant oxygen microsensor), selected to avoid large blood vessels. An average of percent fractional changes of $\mathrm{Hbr}$ and $\mathrm{Hbt}$ at each time point in those two ROIs was used for further analysis.

For all data, statistical significance was determined with ANOVA and 

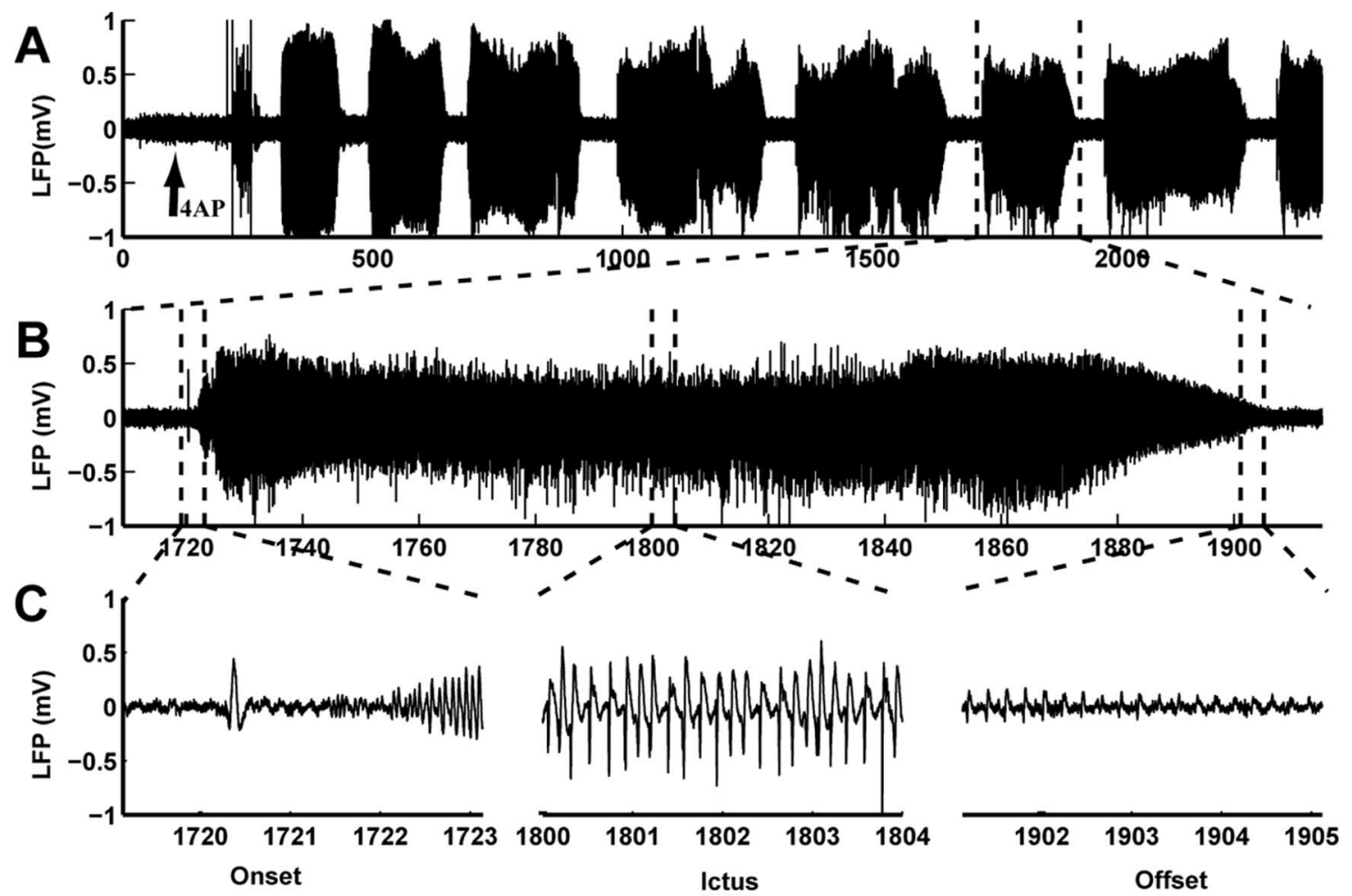

Time (Sec)

Figure 1. Electrophysiology of 4-AP seizure. A, An example of LFP recording demonstrates several ictal discharges following a single 4-AP injection. The arrow highlights the 4-AP injection time. $B$, An expanded view of a single ictal discharge. C, Further expended view shows the evolution of the ictal discharge starting with the onset (focal spike and recruiting rhythm), development of intermittent spike-and-wave activity, and gradual ictal offset.

post hoc tests comparing the baseline mean (SD) measurement of results averaged over all seizures in all animals for the $2 \mathrm{~s}$ baseline before the seizure onset with the mean (SD) values following seizure onset for each time point. All data were expressed as means \pm SE of mean (SE). We used SPSS or Matlab for statistical analyses. Comparisons between optical data and either tissue $\mathrm{pO}_{2}$ or Doppler measurements were performed with two-tailed $t$ tests with Welch correction assuming unequal SDs and also with regression models.

\section{Results}

Acute focal 4-AP seizures

Ictal discharges were induced by local injection of 4-AP and recorded with an adjacent LFP electrode. One hundred and eightynine seizures were recorded in 11 rats. Spontaneous ictal discharges occurred periodically for up to $2 \mathrm{~h}$ with mean $( \pm \mathrm{SE})$ duration of $96.9 \pm 3.1 \mathrm{~s}$ and an interseizure interval of $20 \sim 600 \mathrm{~s}$. Interictal spikes also occasionally occurred with varying frequency during the interseizure intervals (Fig. 1A). 4-AP ictal discharges typically initiated with a large biphasic spike. These spikes were identical in shape and amplitude to the occasionally observed interictal spikes (Fig. $1 B$ ). The initial spike was typically followed by a low-amplitude fast activity with progressive increase in amplitude (recruiting rhythm), then a period of rapid spike and wave activity and a gradual decrease in spike frequency and amplitude at the offset of the seizure (Fig. 1C).

Cerebral blood flow in the focus and surround during the ictal discharge

LDF, which measures changes in red cell velocity and concentration, was used to detect changes in CBF simultaneously in the focus and in the surrounding cortex (Fig. 2). To determine if cross-contamination occurred between the two probes, the effect of illuminating and extinguishing one probe was recorded in a second probe at varying distances. The cross-talk between our two custom LDF probes in the cortex was $\sim 2.9 \pm 0.5 \%$ (supplemental data and Fig. S1, available at www.jneurosci.org as supplemental material). After ictal onset, an increase in CBF was recorded in the focus that persisted for the duration of the seizure. In the surrounding cortex, on the other hand, a transient decrease in CBF occurred followed by an increase. Although Figure 2 is an example from a single animal, similar results were obtained from all animals. LDF was measured in a total of $85 \mathrm{ictal}$ discharges from 5 rats (Table 1; see Fig. 4). Averaged data revealed that in the focus, a significant increase in CBF was identified at $2.94 \pm 2.6 \mathrm{~s}$ and peaked at $37.7 \pm 8.5 \mathrm{~s}$ after ictal onset. The maximal amplitude of this change was $55.6 \pm 7.8 \%$ of baseline and the increase persisted for a few seconds following the termination of the seizure (Table 1). In this group of animals, the average length of the seizures was $113.3 \pm 16 \mathrm{~s}$, thus the blood flow changes outlasted the duration of the seizure by $\sim 15 \mathrm{~s}$. CBF in the surround, on the other hand, significantly decreased at $2.2 \pm 0.9 \mathrm{~s}$ after the ictal onset and the mean amplitude of the negative CBF peak was $-20.6 \pm 6.8 \%$. The duration of the decrease in the surround was, on average, $10.6 \pm 8.9 \mathrm{~s}$ and thus a transient event at the onset of the seizure (Table 1). The CBF signal in the surround was biphasic and ultimately increased after the transient decrease, as the seizure spread to recruit the surrounding cortex.

Tissue oxygenation in the focus and surround during an ictal discharge

We measured the partial pressure of tissue oxygen $\left(\mathrm{pO}_{2}\right)$ directly with a Clark-style polarographic oxygen microelectrode. To 
A

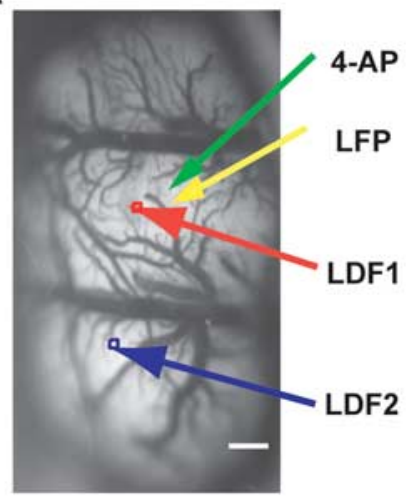

C

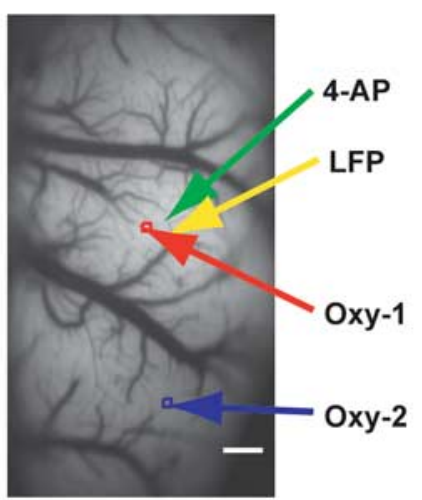

B
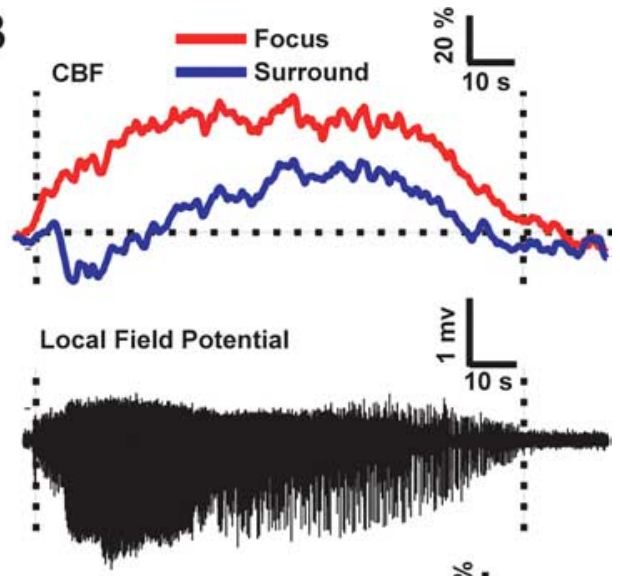

D Oxygenation Change
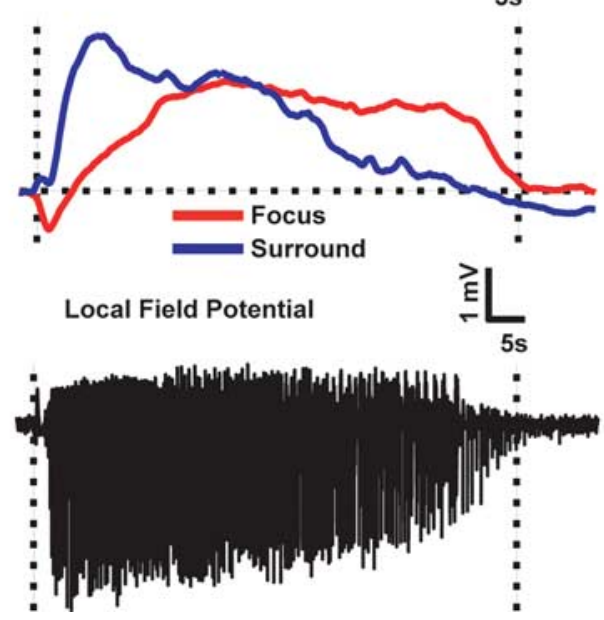

Figure 2. Recordings of $\left(B F\right.$ and $\mathrm{p}_{2}$ in the focus and surround. $A$, Image $(570 \mathrm{~nm})$ of cortical surface demonstrating positions of 4-AP (green) and LFP electrodes (yellow), and both LDF probes (red, focus; blue, surround). Scale bar, $500 \mu \mathrm{m} . B$, CBF has a monophasic increase the focus and a biphasic transient decrease in the surround, followed by a later increase. Scale bar, $500 \mu \mathrm{m}$. C, Image $(570 \mathrm{~nm})$ of cortical surface demonstrating positions of 4-AP and LFP electrodes and $\mathrm{pO}_{2}$ probes (red, focus; blue, surround). $D$, Seizures induce a transient dip in tissue $\mathrm{pO}_{2}$ followed by an increase in $\mathrm{pO}_{2}$ in the focus. A sustained increase in $\mathrm{pO}_{2}$ exists in the surround that decreases more quickly than in the focus. The dashed lines showed the ictal onset (left) and offset (right).

study simultaneously the changes of tissue oxygenation in the focus and surround, two separate oxygen electrodes were placed both adjacent and distant from the 4-AP electrode (Fig. 2C). An example of the change in $\mathrm{pO}_{2}$ in the focus and surround from a single animal is shown in Figure $2 D$. In the ictal focus, the typical $\mathrm{pO}_{2}$ was biphasic with an early dip after ictal onset (deoxygenation), followed by a longer duration increase in $\mathrm{pO}_{2}$ (hyperoxygenation).

Averaged data in 104 seizures ( $n=6$ rats), showed that in the focus the mean amplitude of the $\mathrm{pO}_{2}$ initial dip peak was $-22.8 \pm 2.1 \%$ with a duration of $13.6 \pm 2.9 \mathrm{~s}$ (Table 1; see Fig. 4 ) and an onset latency of $1.6 \pm 0.9 \mathrm{~s}$ following the initiation of the seizure. Tissue $\mathrm{pO}_{2}$ was biphasic in the focus and following the initial deoxygenation we recorded a larger, longer period of hyperoxygenation that reached a peak amplitude of $32.5 \pm$ $6.8 \%$ and lasted for $45.2 \pm 4.7 \mathrm{~s}$. In this group of animals, the average duration of the seizures was $82.2 \pm 10 \mathrm{~s}$. Although in some cases the oxygen signal returned to baseline simultaneously with the offset of the seizure, on average, tissue $\mathrm{pO}_{2}$ returned to baseline $\sim 20 \mathrm{~s}$ before seizure termination. At a distance from the ictal focus, in the surround, the $\mathrm{pO}_{2}$ was monophasic and significantly increased within $3.3 \pm 1.1 \mathrm{~s}$ of

ictal onset to a peak amplitude of $33.6 \pm$ $12.5 \%$ that lasted $42.6 \pm 6.5$ s, returning to baseline before the offset of the seizure (see Fig. 4). These data indicate that the influx of blood into the focus is inadequate to perfuse the hypermetabolic neurons for $\sim 10 \mathrm{~s}$, after which there is a period of hyperperfusion and hyperoxygenation.

\section{Optical spectroscopic imaging of} ictal discharge

Because Doppler probes and oxygen electrodes only sample local adjacent cortex, we increased our spatial sampling with the use of optical imaging. IOS, however, does not measure precisely the same physiologic events as LDF and oxygen electrodes since the optical signal is sensitive to hemoglobin oxygenation rather than $\mathrm{CBF}$ or tissue $\mathrm{pO}_{2}$. However, correlations between tissue $\mathrm{pO}_{2}$ or CBF and the IOS data permitted us to address several additional questions. First, how well does hemoglobin oxygenation correlate with direct measurements of tissue $\mathrm{pO}_{2}$ ? Are these coupled or uncoupled during epileptic events? Second, what is the correlation between CBF and CBV (Hbt)? These data are particularly useful since they are relevant to the BOLD signals measured with fMRI, a technique that is increasingly being used clinically to make decisions about the treatments of patients with epilepsy.

In these experiments we were able to measure tissue $\mathrm{pO}_{2}$ simultaneously from the focus and surround while measuring the IOS (Fig. 3). A total of 25 seizures $(n=$ 6 rats) were recorded, and results were averaged together. The average length of seizures in this group of animals was $77.2 \pm$ $10 \mathrm{~s}$. The Hbr signal also showed a transient dip in hemoglobin oxygenation (increase in Hbr) at the onset of the seizures. The hemoglobin oxygenation dip began at $0.7 \pm 0.6 \mathrm{~s}$, and peaked at $0.9 \pm 0.1 \mathrm{~s}$ (Table 1 ; Fig. 4 ). The duration of the hemoglobin oxygen dip was $3.79 \pm 0.9 \mathrm{~s}$ with a peak amplitude of $5.9 \pm$ $1.6 \%$. The hemoglobin oxygen dip was shorter in duration by one-third compared with the dip in tissue $\mathrm{pO}_{2}(p<0.01)$. Like the $\mathrm{pO}_{2}$ measurements, the Hbr signal was also biphasic showing a delayed increase in hemoglobin oxygenation (decrease in $\mathrm{Hbr}$ ) in the focus that had an average peak amplitude of $-5.7 \pm 1.1 \%$ and a duration of $47.8 \pm 9.3 \mathrm{~s}$. This delayed hyperoxygenation of hemoglobin was not statistically different in duration than the delayed increase in tissue $\mathrm{pO}_{2}(p>$ 0.05 ) (Table 1). In the surround, Hbr decreased by $3.1 \pm 1.9 \%$ with a duration of $40.5 \pm 10.1 \mathrm{~s}$, which was of equal duration as the increase in tissue $\mathrm{pO}_{2}$ in the surround. Although the percent change in the amplitude of the $\mathrm{pO}_{2}$ signal was much larger than the corresponding percent change in $\mathrm{Hbr}$, it is difficult to directly compare these signals since they are measured in different units and have different baseline fluctuations in signal-to-noise.

Our IOS measurements also provided a measurement of $\mathrm{Hbt}$ 
Table 1. Temporal characteristics of $\mathrm{LDF}, \mathrm{pO}_{2}$, and $\mathrm{IOS}$

\begin{tabular}{|c|c|c|c|c|c|c|c|c|}
\hline & \multicolumn{2}{|l|}{ CBF } & \multicolumn{2}{|l|}{$\mathrm{pO}_{2}$} & \multicolumn{2}{|l|}{$\mathrm{Hbr}$} & \multicolumn{2}{|l|}{$\mathrm{Hbt}$} \\
\hline & Focus & Surround & Focus & Surround & Focus & Surround & Focus & Surround \\
\hline Onset latency (s) & $2.94 \pm 2.6$ & $2.2 \pm 0.9$ & $1.6 \pm 0.9$ & $3.3 \pm 1.1$ & $0.7 \pm 0.6$ & $9.1 \pm 4.9$ & $0.8 \pm 0.9$ & $7.3 \pm 5.4$ \\
\hline \multicolumn{9}{|l|}{ Decrease } \\
\hline Amplitude (\%) & & $-20.6 \pm 6.8$ & $-22.8 \pm 2.1$ & & $-7.7 \pm 1.1$ & $-3.1 \pm 1.9$ & & $-1.2 \pm 1.8$ \\
\hline Duration (s) & & $10.6 \pm 8.9$ & $13.6 \pm 2.9$ & & $47.8 \pm 9.3$ & $40.5 \pm 10.1$ & & $21.3 \pm 5.6$ \\
\hline Time to peak (s) & & $4.5 \pm 2.1$ & $6.8 \pm 3.2$ & & $31.7 \pm 7.5$ & $20.2 \pm 8.7$ & & $10.5 \pm 3.7$ \\
\hline \multicolumn{9}{|l|}{ Increase } \\
\hline Amplitude (\%) & $55.6 \pm 7.8$ & $10.2 \pm 6.3$ & $32.5 \pm 4.3$ & $33.6 \pm 12.5$ & $5.9 \pm 1.6$ & & $7.2 \pm 1.5$ & \\
\hline Duration (s) & $134 \pm 15.6$ & $15.2 \pm 8.6$ & $45.2 \pm 4.7$ & $42.6 \pm 6.5$ & $3.7 \pm 0.85$ & & $49.6 \pm 9.3$ & \\
\hline Time to peak (s) & $37.7 \pm 8.5$ & $13.6 \pm 6.9$ & $8.3 \pm 3.1$ & $15.3 \pm 3.3$ & $0.9 \pm 0.1$ & & $29.3 \pm 6.5$ & \\
\hline
\end{tabular}

For biphasic events, both increases and decreases are reported. CBF (Surround): the decrease occurs first; $\mathrm{pO}_{2}$ (Focus): the decrease occurs first; Hbr (Focus): the increase occurs first. The onset latency refers to the first statistically significant change following the onset of the seizure.

Value are means $\pm \mathrm{SE}$. CBF ( $n=85$ seizures; 5 rats), $\mathrm{pO}_{2}$ ( $n=104$ seizures; 6 rats), Hbt, and $\mathrm{Hbt}$ ( $n=25$ seizures; 6 rats).
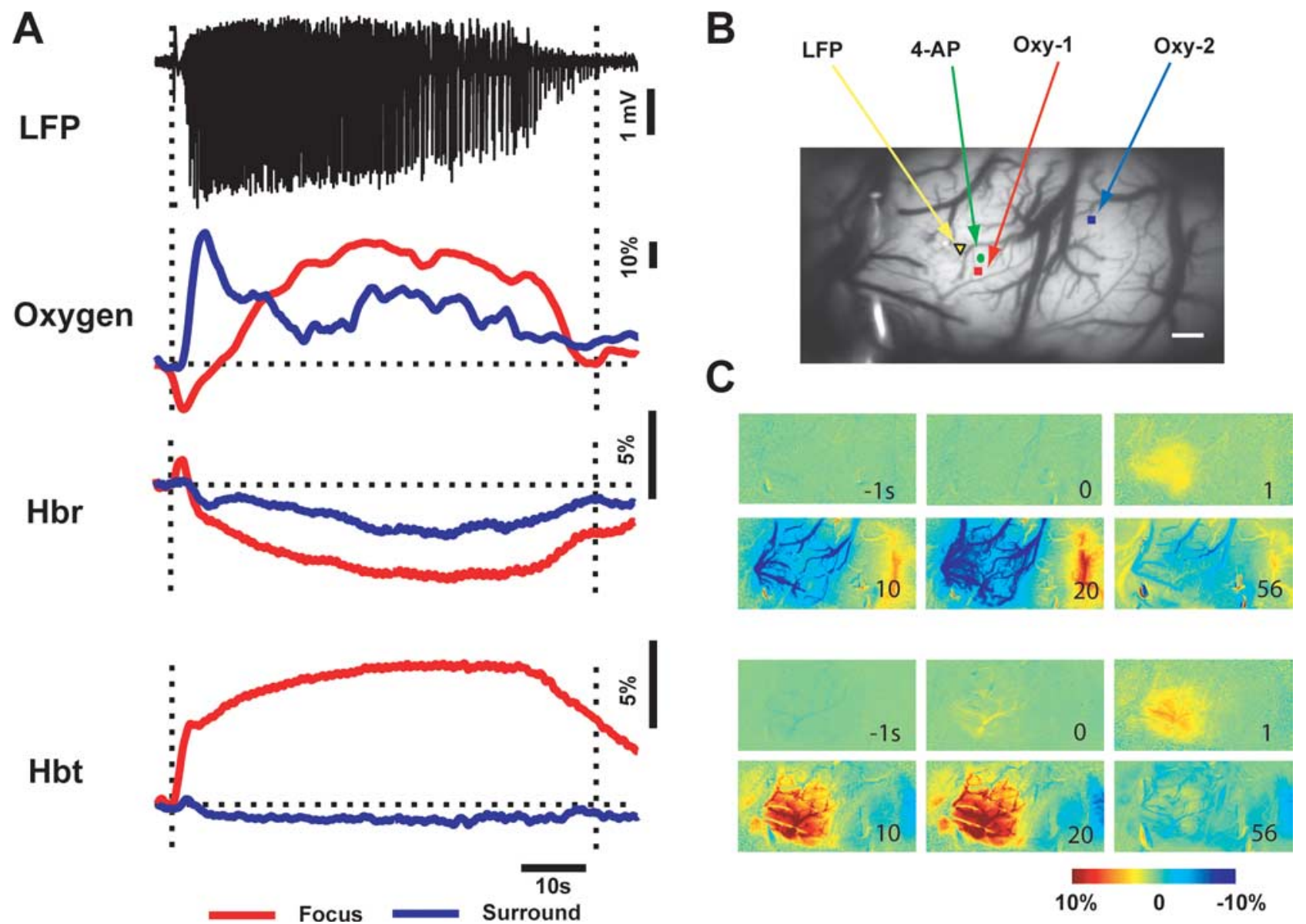

Figure 3. Simultaneous oxygen electrode and $\mathrm{IOS}$ measurements of $\mathrm{pO}_{2}, \mathrm{Hbr}$, and $\mathrm{Hbt}$ during ictal discharge. $A$, Time course of LFP indicates onset, evolution, and offset of seizure (dotted lines). Simultaneous measurements of tissue $\mathrm{pO}_{2}$, Hbt concentration, and $\mathrm{Hbr}$ concentration from the focus and surround are time-locked with the course of the seizure. Note that a small transient dip in tissue $\mathrm{pO}_{2}$ and increase in $\mathrm{Hbr}$ occur in the focus at the onset of the seizure, followed by a longer hyperoxygenation despite an increase in $\mathrm{Hbt}$. In contrast, measurements from the surround reveal only hyperoxygenation and a decrease in $\mathrm{Hbt}$. $\boldsymbol{B}$, Image of cortical surface $(570 \mathrm{~nm}$ ) to demonstrate locations of 4-AP (yellow), LFP electrode (green), oxygen microsensor in focus (red) and in surround (blue). Two square dots are the locations of the ROls in the focus (red) and surround (blue) shown in $\boldsymbol{A}$ (bottom plots of Hbr and Hbt). Scale bar, $500 \mu \mathrm{m}$. C, Hbr images at selected time points with respect to seizure onset (top) show short increase in Hbr in the parenchyma of the focus followed by a longer, more widespread decrease in $\mathrm{Hbr}$ in the draining veins. Hbt images at similar time points (bottom) show an increase in $\mathrm{Hbt}$ in the arteries and capillaries in the focus with a small persistent decrease in the surround.

during ictal onset, evolution and offset from the surface of the cortex, which corresponds with CBV (Fig. 3). Within $0.8 \pm 0.9 \mathrm{~s}$ of the electrographic onset of the seizure, the Hbt signal increased to a maximum amplitude of $7.2 \pm 1.5 \%$ in the focus (Fig. 4). The Hbt increase lasted for $49.6 \pm 9.3 \mathrm{~s}$, which was significantly shorter than the duration of the electrographic seizures $(p<$ 0.001). In the surround, the Hbt signal decreased slowly, begin- ning $7.3 \pm 5.4 \mathrm{~s}$ after ictal onset to an average peak amplitude of $-1.2 \pm 1.8 \%$ (Figs. 3, 4). On average, the decrease in Hbt lasted for $21.8 \pm 5.6 \mathrm{~s}$, which was longer than the decrease in CBF, likely caused by the location of the ROI and the limited sampling of ROI measurements.

Figure 4 displays the $\mathrm{CBF}, \mathrm{pO}_{2}, \mathrm{Hbr}$, and $\mathrm{Hbt}$ changes averaged over all animals at seizure onset for comparison. 


\section{A}

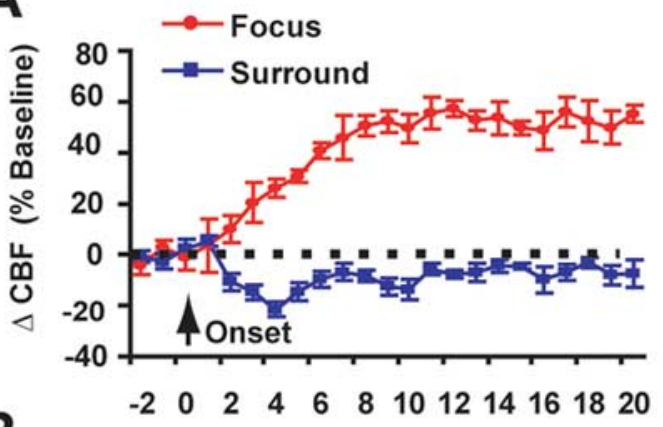

B

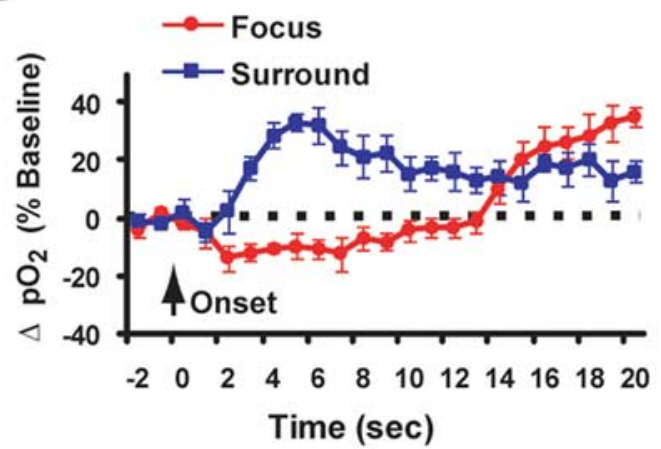

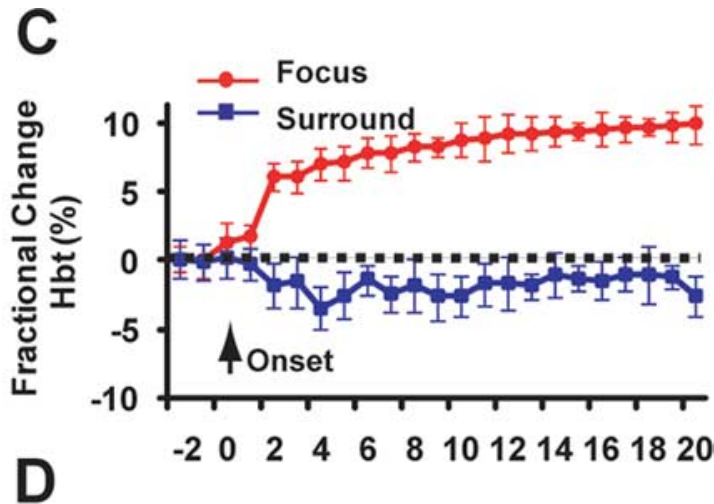

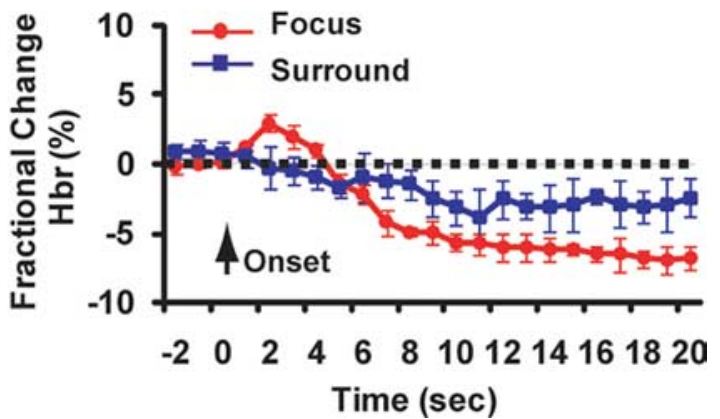

Figure 4. Average results of $\mathrm{CBF}, \mathrm{pO}_{2}, \mathrm{Hbr}$, and $\mathrm{Hbt}$ after ictal onset in the focus and the surround for the first $20 \mathrm{~s}$. Because each seizure has a different duration and morphology, it is impossible to average the entire length of the seizure. Only seizure onset is uniform. $\boldsymbol{A}$, Mean percent change in (BF during ictal discharges ( $n=85$ seizures, 5 rats). $\boldsymbol{B}$, Mean percentage change in tissue $\mathrm{p} \mathbf{O}_{2}$ ( $n=104$ seizures, 6 rats). C, $\boldsymbol{D}$, Mean fractional change in $\mathrm{Hbt}(\boldsymbol{C})$ and $\mathrm{Hbr}(\boldsymbol{D})$ after ictal onset ( $n=25$ seizures, 6 rats). The arrow shows the ictal onset. The dashed line demonstrates the baseline before the ictal discharge. Error bars indicate SEM.

\section{Correlation between duration of seizure and perfusion/oximetry changes}

Because the duration and electrographic morphology of each seizure varies over time, examination of averaged data can potentially overlook correlations between hemodynamic and electrographic information. For this reason we plotted seizure duration against the duration of the hemodynamic events. Neither the duration of the increase in $\mathrm{Hbr}$ nor the duration of initial decrease in tissue $\mathrm{pO}_{2}$ in the focus correlated with the duration of ictal discharge (Fig. 5A). However, both the duration of the later decrease in $\mathrm{Hbr}$ and the increase in tissue $\mathrm{pO}_{2}$ measured from the focus correlated with the ictal discharge duration (Fig. 5B). Likewise, the duration of the increase in $\mathrm{Hbt}$ and increase in $\mathrm{CBF}$ also strongly correlated with the seizure duration (Fig. 5C,D). These results suggest that measures of perfusion such as $\mathrm{CBF}$ and $\mathrm{Hbt}$ (CBV) correlate well with the duration of seizures compared with the duration of the initial dip which is relatively fixed. In fact, IOS imaging of Hbt provided a nearly 1:1 measurement of seizure duration. Similarly, the duration of the later increase in hemoglobin and tissue oxygenation, which are elicited by the influx of oxygenated hemoglobin and comprise a significant proportion of the positive BOLD signal measured with $\mathrm{fMRI}$, also correlate with seizure duration.

\section{Correlation between hemoglobin and tissue oxygenation}

Because the existence of the initial dip during normal sensory processing and epileptic events has been challenged, we performed a direct comparison between the IOS measurements of hemoglobin oxygenation and tissue oxygenation from the focus during seizures in which the two were measured simultaneously. Similar to the average data from all animals described earlier in the paper, the duration of the initial dip in hemoglobin oxygen- ation, or increase in $\mathrm{Hbr}$, was significantly shorter than the duration of the decrease in tissue $\mathrm{pO}_{2}$ (Table 1$)(p<0.001)$.

To elucidate the conversion function between the initial decrease in $\mathrm{pO}_{2}$ and the increase in $\mathrm{Hbr}$ (initial dip), we plotted the maximal amplitude of each signal for each seizure in which both were recorded simultaneously (Fig. 6). A larger decrease in tissue $\mathrm{pO}_{2}$ elicited a larger increase in $\mathrm{Hbr}$. This correlation was statistically significant with both linear and polynomial equations (Fig. 6). The polynomial model, however, fit the data significantly better than the linear equation ( $F$ statistic, $p=0.008$ ). This result is biologically significant since it implies that the relationship between tissue $\mathrm{pO}_{2}$ and $\mathrm{Hbr}$ is not linear. More specifically, smaller decreases in tissue $\mathrm{pO}_{2}$ elicited a variable hemodynamic dip, whereas larger decreases in tissue $\mathrm{pO}_{2}$ more consistently elicited a larger hemodynamic dip.

Temporal dependence of perfusion and oximetry in epilepsy Because epilepsy is a dynamic neuronal event that evolves over time, mechanisms of neurovascular coupling may not be static. This is a contrast to studies of brief sensory stimulation in which a steady state may exist. We thus investigated the temporal dependence of the relationship between $\mathrm{pO}_{2}$ and $\mathrm{Hbr}$ by plotting the resulting data points for each second during the first $20 \mathrm{~s}$ after the onset of the seizure (Fig. 7A). In the relationship of $\mathrm{Hbr}$ and $\mathrm{pO}_{2}$, a general second order polynomial regression provided a better fit than the linear regression, although both were significant $(F$ statistics for best fit, $p=0.008$ ) (Fig. 7A). The data clearly show three stages in the evolution of the seizure. First is the onset, in which there is a dip in $\mathrm{pO}_{2}$ and an increase in $\mathrm{Hbr}$ (Fig. $7 \mathrm{~A}$, green circles). Second is the evolution, in which the dip in $\mathrm{pO}_{2}$ persists but the $\mathrm{Hbr}$ signal inverts as the concentration of oxygenated hemoglobin increases despite the dip on tissue $\mathrm{pO}_{2}$. Finally, 
tissue $\mathrm{pO}_{2}$ becomes hyperoxygenated as does hemoglobin (seen in the top left of the graph in Fig. 7A).

A similar analysis of the evolution of the relationship between $\mathrm{CBF}$ and $\mathrm{Hbt}$ also reveals a temporal dependence; however, only two stages are apparent (Fig. $7 B$ ). In the regression analysis of $\mathrm{CBF}$ and $\mathrm{Hbt}$, the linear model, the polynomial model, and the power model were all significant, although the power regression had a better fit than the linear regression and the polynomial regression ( $F$ statistics, $p=0.004$ and $p=0.03$, respectively). There is no steady state at the onset of the seizure but rather a rapid increase in $\mathrm{CBF}$ and $\mathrm{Hbt}$ as the seizure evolves and then a later steady state with a fractionally greater increase in CBF than $\mathrm{Hbt}$ (seen in top right of the graph in Fig. 7A). This result supports a nonlinear relationship between $\mathrm{CBF}$ and $\mathrm{CBV}$, commonly known as the Grubb's power law (Grubb et al., 1974; Martin et al., 2006).

\section{Discussion}

The principal finding of this study is that tissue oxygenation undergoes a biphasic response to ictal events. An initial dip is followed by a longer duration period of hyperoxygenation that often outlasts the duration of the seizure. These tissue oxygenation changes are more profound and longer in duration than indirect optical measurements of hemoglobin oxygenation and occur despite enormous increases in $\mathrm{CBF}$. Hence, cerebrovascular autoregulation is temporarily unable to meet the increased metabolic demands in the zone of ictal onset and the degree of this neurovascular mismatch is underestimated by both fMRI and IOS. A second significant finding is the decrease in blood flow in the surrounding brain. This drop occurs almost simultaneously with the rise in CBF in the focus and contributes to the negative signals observed around a seizure focus.

\section{Transient dip in tissue oxygenation during seizures}

There is little debate that seizures elicit a dramatic, sustained increase in the metabolism of both oxygen $\left(\mathrm{CMRO}_{2}\right)($ Meldrum and Nilsson, 1976) and glucose ( $\left.\mathrm{CMR}_{\text {gluc }}\right)$ (Engel et al., 1982). As a result, the brain vasodilates the local vasculature to direct oxygenated blood to the hypermetabolic neurons leading to an increase in CBF in the focus (Kreisman et al., 1991; Nersesyan et al., $2004 \mathrm{~b}$ ). Although the inadequacy of CBF to meet metabolic demand has been demonstrated in animal models of status epilepticus, primarily caused by systemic collapse after $1-2 \mathrm{~h}$ of seizures (Kreisman et al., 1991) there has been little evidence of inadequate oxygenation at the onset or throughout shorter duration ictal events (Martin and Halsey, 1983; Nersesyan et al., 2004a). Although early studies postulated that hypoxia may contribute to neuronal injury during seizures (Plum et al., 1968; Simon, 1985), this hypothesis was rejected once it was discovered that excitotoxic injury can occur in areas of the brain that are not hypoxic (Meldrum, 2002) and that the percent increase in CBF surpassed
B Late "BOLD-like" Response

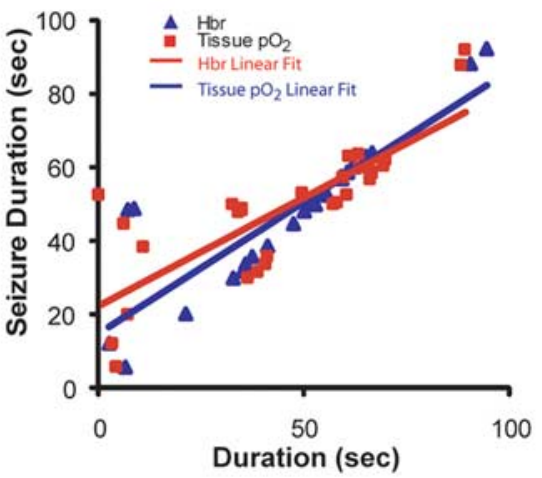

D Total Hemoglobin

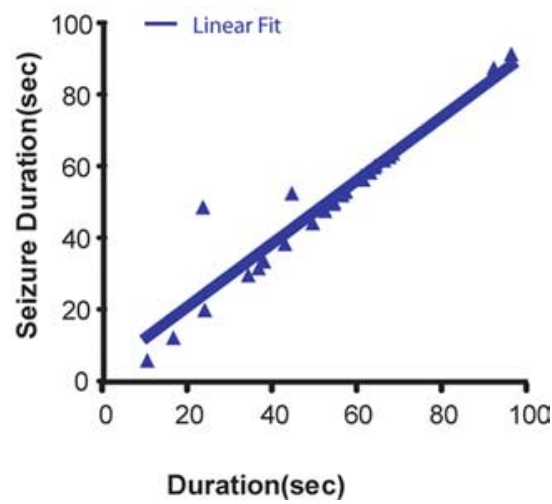

Duration(sec)
Duration (sec)

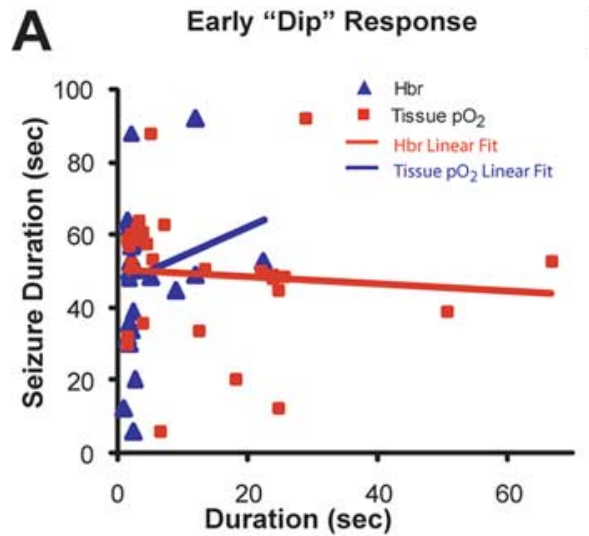

Figure 5. Correlation between length of ictal discharge and duration of perfusion/oximetry responses in the focus. $\boldsymbol{A}$, Relationship between duration of seizure and duration of early "dip" in tissue $\mathrm{pO}_{2}$ and increase in Hbr. The regression lines were as follows: (Hbr linear fit) $y=833.83 x-10953, R^{2}=0.0067, p=0.17 ;\left(p 0_{2}\right.$ linear fit) $y=-0.096 x+50.4, R^{2}=0.006, p=$ in CBF. The linear regression line was $y=0.649 x+47.64, R^{2}=0.547, p<0.02$ ( $n=85$ seizures). $D$, Relationship between seizure duration and increase in $\mathrm{Hbt}$. The linear regression line was $y=0.884 x+3.62, R^{2}=0.89, p<0.0001$ ( $n=25$ seizures).

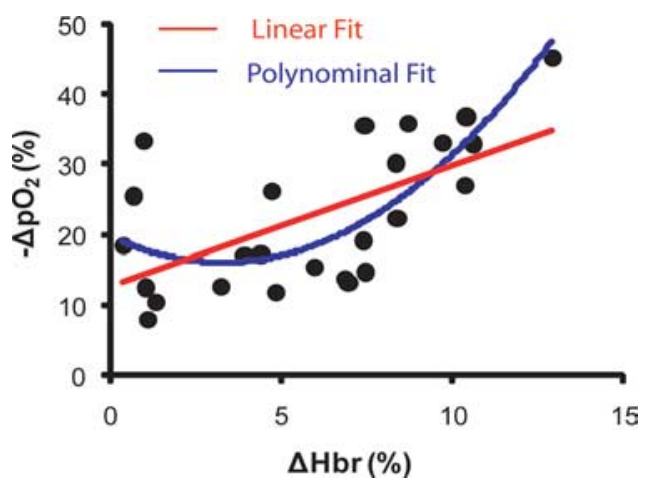

Figure 6. Comparison between the initial dip in hemoglobin oxygenation and the early dip in tissue oxygenation in the focus. The peak decrease in $\mathrm{p}_{2}$ plotted against the peak increase in $\mathrm{Hbr}$ for those seizures in which both were measured simultaneously. The regression lines were as follows: (linear fit) $y=1.715 x+12.66, R^{2}=0.374, p=0.002$; (polynomial fit) $y=$ $0.339 x^{2}-2.22 x+19.72, R^{2}=0.551, p=0.008$ ( $n=25$ seizures).

the percent increase $\mathrm{CMR}_{\text {gluc }}$ (Horton et al., 1980; Siesjö et al., 1986).

In fact, it has been generally accepted that perfusion is adequate to meet metabolic demand during epileptic events (Ingvar, 1986). Indeed, we show in the 4-AP model that ictal events elicit 
A

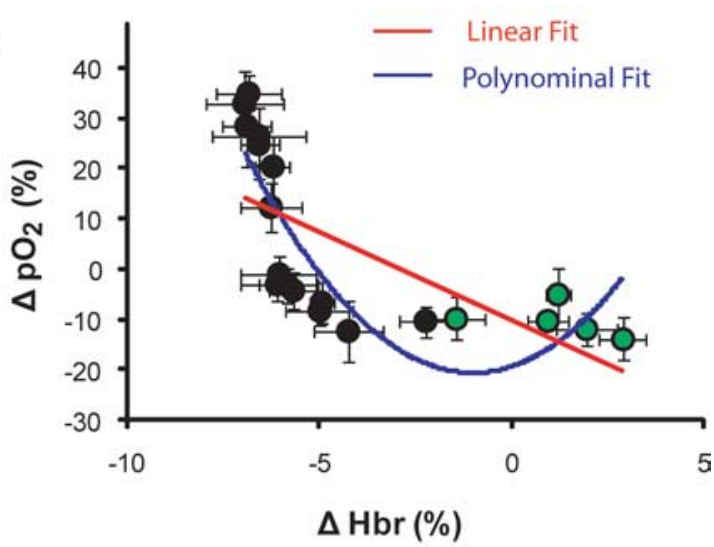

B

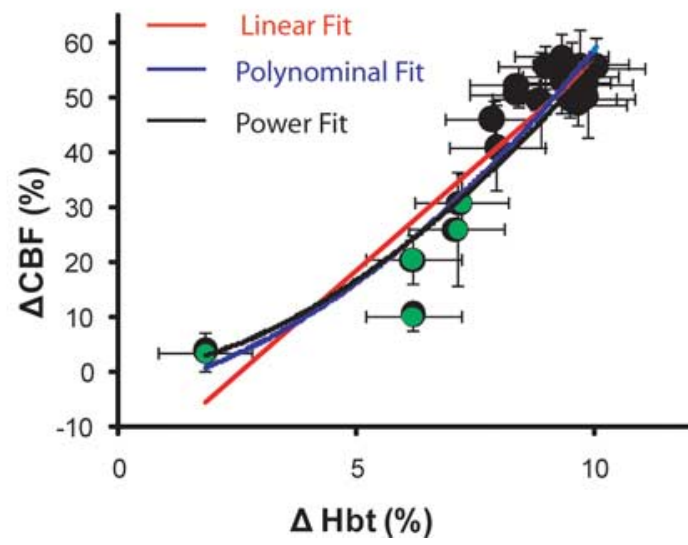

Figure 7. Temporal dependence of conversion between $\mathrm{Hbr}$ versus $\mathrm{pO}_{2}$ and $\mathrm{Hbt}$ versus CBF during the first 20 s of the seizure. $A$, Plot of $\mathrm{Hbr}$ and $\mathrm{p}_{2}$ in the focus for each of the first 20 s after ictal onset. The width and height of the circles represents the SEM for the $\mathrm{Hbr}_{\text {and }} \mathrm{pO}_{2}$. Data points from the first $5 \mathrm{~s}$ were shaded green. The regression lines were as follows: (linear fit) $y=-3.47 x-9.9, R^{2}=0.447, p=0.003 ;$ (polynomial fit) $y=1.24 x^{2}+2.48 x-19.19, R^{2}$ $=0.771 ; p=0.0026$ ( $n=6$ rats). $B$, Plot of $\mathrm{Hbt}$ and $(\mathrm{BF}$ for the first $20 \mathrm{~s}$ of the seizure. Data points from the first $5 \mathrm{~s}$ were shaded green. The width and height of the circles represents the SEM for Hbt and CBF. The regression lines were as follows: (linear fit) $y=7.55 x-19.49, R^{2}=$ $0.829, p=0.0001$; (polynomial fit) $y=0.445 x^{2}+1.856 x-4.408, R^{2}=0.852, p=0.0001$; (power fit) $y=0.984 x^{1.757}, R^{2}=0.882, p=0.00005$. Hbr: $n=6$ rats; CBF: $n=5$ rats.

a $50 \%$ increase in CBF, which persist throughout the length of the seizure. Nevertheless, a transient of $23 \%$ decrease in $\mathrm{pO}_{2}$ occurs which is much larger than the $3-4 \%$ decrease reported in studies of normal somatosensory processing (Thompson et al., 2003). How do we reconcile our data with the literature? Most prior studies used techniques with lower spatial and temporal resolution such as mass spectrometry (Pinard et al., 1987), spectrophotometry measurements of venous outflow oxygen saturation (Blennow et al., 1979), fMRI (Nersesyan et al., 2004a) and near infrared spectroscopy (Hoshi and Tamura, 1992). Because the dip in tissue oxygenation is focal, transient and followed by a larger, widespread hyperoxygenation, it would be easy to miss.

The relationship between tissue and hemoglobin oxygenation We also shown that when direct tissue oxygenation measurements are made simultaneously with noninvasive measurements of hemoglobin oxygenation, the latter underestimate the relative change in tissue oxygen. This is true both of the oxygen undershoot at the beginning of the seizure as well as for the overshoot during the majority of the duration of the seizure. The etiology of the dip is thought to be the utilization of mitochondrial $\mathrm{O}_{2}$ stores required to replenish the ATP used to restore ion gradients and recycle neurotransmitters (Ances, 2004). Since oxygen diffuses from the vascular compartments to the tissues based on a diffusion gradient (Zheng et al., 2005; Hermán et al., 2006) then the drop in tissue $\mathrm{pO}_{2}$ must be sufficiently large to drive the diffusion gradient. In epilepsy, there is a pathologically high increase in $\mathrm{CMRO}_{2}$. While the diffusion of oxygen may be linear over the normal range, as the demand rises to supranormal levels, we have demonstrated nonlinearities, which cause a more profound and longer duration dip in the tissue than is observed in hemoglobin.

\section{Inverted optical signal in the surround}

In the mid-1960s, Prince and Wilder (1967) described a ring of inhibitory activity around an acute interictal focus in an animal model which they called the "inhibitory surround." This finding was reproduced by other investigators during interictal events in vivo (Goldensohn et al., 1977; Schwartz and Bonhoeffer, 2001) and during seizure-like events in vitro (Trevelyan et al., 2006). During normal cortical processing negative BOLD signals correlate with these decreases in neuronal activity in some studies (Shmuel et al., 2006), while other studies have demonstrated that these negative BOLD signals correlate with inhibitory synaptic activity but not firing rates (Devor et al., 2007) or find that negative BOLD only correlates with decreases in CBF (Harel et al., 2002). However, a decrease in BOLD in the surround is the opposite of the decrease in $\mathrm{Hbr}$, which we describe.

Our data indicate a clear decrease in CBF measured with LDF as well as a decrease in CBV measured optically in the surrounding cortex. These findings could not be caused by cross-talk between the two Doppler probes as the maximal effect upon extinguishing one probe was $\sim 3 \%$ change and probes were never turned off at any time during the experiments and our epileptic signal changes were much larger than this cross-contamination. At the same time, tissue and hemoglobin oxygenation increase despite this decrease in the influx of oxygenated hemoglobin. These data are consistent with a decrease in $\mathrm{CMRO}_{2}$ in the surrounding tissue as a result of a decrease in neuronal activity, which is proportionally greater than the decrease in CBF. It is not clear if this decrease in CBF is a "vascular steal" phenomenon, unrelated to neuronal activity (Woolsey et al., 1996) or a result of intact neurovascular coupling in areas of decreased $\mathrm{CMRO}_{2}$ related to relative neural inactivity (Gold and Lauritzen, 2002). In this latter case, although CBF is decreased, there is a breakdown in neurovascular coupling in the surrounding areas since the relative decrease in $\mathrm{CMRO}_{2}$ is out of proportion with the decrease in $\mathrm{CBF}$, hence the rise in $\mathrm{pO}_{2}$ and decrease in $\mathrm{Hbr}$. It is thus possible that neither shunting nor steal occur but on the contrary, that there is relatively more CBF than one would expect given the decrease in metabolism, which could be attributed to a generalized nonspecific increase in CBF in the surround that spills over from the focus. Although merely speculation, possible etiologies for this transient decrease in metabolism in the surround include feedforward inhibition, upregulation of local inhibitory neuronal tone, decreases in glial metabolism or pericyte and upstream arteriolars relaxation (Trevelyan et al., 2006).

The simplest explanation is a passive model whereby vasodilation propagates upstream in a stepwise manner. Early in the seizure, vasodilation within and around the focus shunts blood from the surround to the focus. This vasodilation could not be due to direct injection of 4-AP, a known vasoconstrictor (Sobey and Faraci, 1999; Quan and Sobey, 2000). As vasodilation propagates further upstream, CBF increases in the surround as well. In brief, neuronal activity causes local vasodilation through activation of metabotropic glutamate receptors on astrocytes, which 
initiates propagating calcium waves. Elevated calcium in end-feet cause dilation of arterioles via prostaglandin E2 and modestly elevated levels of potassium (Mulligan and MacVicar, 2004; Takano et al., 2006; Winship et al., 2007). In addition, pericytes causes local vasodilation of capillaries. Propagated vasodilation to upstream vessels initiates widespread increases in CBF through electrotonic coupling of endothelia and calcium waves (Iadecola et al., 1997). An alternative hypothesis involves decreases in neuronal activity in the surround which may cause decreases in $\mathrm{pCO}_{2}, \mathrm{NO}$ and adenosine and increases in $\mathrm{pO}_{2}$ and $\mathrm{pH}$ that may also contribute to distant vasoconstriction, just as the opposite effects cause vasodilation in the focus (Peppiatt et al., 2006). Further mechanistic studies will be required to tease out these effects.

\section{The relationship between $\mathrm{CBF}$ and $\mathrm{Hbt}$}

$\mathrm{Hbt}$ is proportional to $\mathrm{CBV}$, assuming constant hematocrit (Nemoto et al., 2004). The relationship between CBF and CBV in the steady-state is best described by Grubb's law (Grubb et al., 1974). Increases in CBF elicit a fractionally smaller increase in $\mathrm{CBV}$, which varies with the cube root of CBF. Further increases in $\mathrm{CBF}$ elicit fractionally smaller increases in $\mathrm{CBV}$, since the compliance of the brain limits the ability of this vascular compartment to increase (Buxton et al., 2004; Zheng et al., 2005; Huppert et al., 2007). Our data demonstrate that, although the power fit had the highest correlation, a linear model is a reasonable description of the relationship between $\mathrm{CBF}$ and $\mathrm{CBV}$ during the initiation and evolution of the seizure. We found that the increase in $\mathrm{CBF}$ was $\sim 7$ times the increase in CBV. This is a proportionally greater increase in CBF than CBV compared with what would be expected from Grubb's law. The most likely explanation is that at supranormal increases in $\mathrm{CBF}$ as occurs during seizures, the sigmoidal cerebrovascular autoregulation curve of CBF (Lassen, 1964) saturates at higher values than the CBV curve which is limited by the vascular compliance of the brain (Buxton et al., 2004; Zheng et al., 2005; Huppert et al., 2007). Another possible factor influencing this relationship is the difference in the volume of sampled tissue, being larger for LDF than IOS based on the higher wavelength of LDF light and the smaller size of the IOS ROI. Because we did not measure CBF and Hbt simultaneously, our data must be interpreted with caution. However, the data implies that assumptions about the relationship between $\mathrm{CBF}$ and $\mathrm{CBV}$, which may hold during normal cortical processing, may not be applicable during epilepsy.

\section{Relevance to human epilepsy}

The initial dip during seizures is not just a phenomenon related to acute animal models of epilepsy. Our lab has recently demonstrated that spontaneous human seizures also elicit a dip in hemoglobin oxygenation that can be measured optically and even used to predict seizure onset (Zhao et al., 2007). In fact, human intracranial measurements from the 1960s using gold wire electrodes have shown decreases in tissue oxygen at seizure onset (Cooper et al., 1966; Dymond and Crandall, 1976). Likewise, perfusion increases in the focus and decreases in the surround have also been demonstrated in human brain dating back to the work of Wilder Penfield in the late 1930s, among other investigators (Dymond and Crandall, 1976) (Gibbs, 1933; Penfield et al., 1939; Weinand et al., 1994). Hence, we do not think our findings are necessarily model- or species-specific and may be generalized to chronic human epilepsy.

With regards to clinical relevance, although we have demonstrated a transient focal ischemia in the tissue, there is no indication that any permanent tissue damage will occur during this brief period of time. However, it is certainly possible that repetitive focal seizures could elicit tissue damage if cerebrovascular autoregulation is impaired or systemic blood pressure or oxygenation lowered. Whether hypoxia contributes to the progressive histological and cognitive changes associated with certain types of epilepsy is unknown and will require further investigation. Nevertheless, our data raise the possibility that progressive cognitive decline in certain forms of epilepsy may have a vascular etiology.

\section{References}

Aghakhani Y, Bagshaw AP, Bénar CG, Hawco C, Andermann F, Dubeau F, Gotman J (2004) fMRI activation during spike and wave discharges in diopathic generalized epilepsy. Brain 127:1127-1144.

Ances BM (2004) Coupling of changes in cerebral blood flow with neural activity: what must initially dip must come back up. J Cereb Blood Flow Metab 24:1-6.

Bahar S, Suh M, Zhao M, Schwartz TH (2006) Intrinsic optical signal imaging of neocortical seizures: the 'epileptic dip.' Neuroreport 17:499-503.

Blennow G, Folbergrova J, Nilsson B, Siesjö BK (1979) Cerebral metabolic and circulatory changes in the rat during sustained seizures induced by DL-homocysteine. Brain Res 179:129-146.

Buxton RB, Wong EC, Frank LR (1998) Dynamics of blood flow and oxygenation changes during brain activation: the balloon model. Magn Res Med 39:855-864.

Buxton RB, Uludağ K, Dubowitz DJ, Liu TT (2004) Modeling the hemodynamic response to brain activation. Neuroimage 23:S220-S233.

Cooper R, Crow HJ, Walter WG, Winter AL (1966) Regional control of cerebral vascular reactivity and oxygen supply in man. Brain Res 3:174-191.

Devor A, Tian P, Nishimura N, Teng IC, Hillman EM, Narayanan SN, Ulbert I, Boas DA, Kleinfeld D, Dale AM (2007) Suppressed neuronal activity and concurrent arteriolar vasoconstriction may explain negative blood oxygenation level-dependent signal. J Neurosci 27:4452-4459.

Dymond AM, Crandall PH (1976) Oxygen availability and blood flow in the temporal lobes during spontaneous epileptic seizures in man. Brain Res 102:191-196.

Engel JJ Jr, Kuhl DE, Phelps ME (1982) Patterns of human local cerebral glucose metabolism during epileptic seizures. Science 218:64-66.

Folbergrová J, Ingvar M, Siesjö BK (1981) Metabolic changes in cerebral cortex, hippocampus, and cerebellum during sustained bicucullineinduced seizures. J Neurochem 37:1228-1238.

Frostig RD, Lieke EE, Ts'o DY, Grinvald A (1990) Cortical functional architecture and local coupling between neuronal activity and the microcirculation revealed by in vivo high-resolution optical imaging of intrinsic signals. Proc Natl Acad Sci U S A 87:6082-6086.

Gibbs FA (1933) Cerebral blood flow preceding and accompanying experimental convulsions. Arch Neurol Psychiatry (Chicago) 30:1003-1010.

Girouard H, Iadecola C (2006) Neurovascular coupling in the normal brain and in hypertension, stroke, and Alzheimer disease. J Appl Physiol 100:328-335.

Gold L, Lauritzen M (2002) Neuronal deactivation explains decreased cerebellar blood flow in response to focal cerebral ischemia or suppressec neocortical function. Proc Natl Acad Sci U S A 99:7699-7704.

Goldensohn ES, Zablow L, Salazar A (1977) The penicillin focus. I. Distribution of potential at the cortical surface. Electroencephalogr Clin Neurophysiol 42:480-492.

Grubb RL Jr, Raichle ME, Eichling JO, Ter-Pogossian MM (1974) The effects of changes in $\mathrm{PaCO} 2$ on cerebral blood volume, blood flow, and vascular mean transit time. Stroke 5:630-639.

Haglund MM, Ojemann GA, Hochman DW (1992) Optical imaging of epileptiform and functional activity in human cerebral cortex. Nature 358:668-671

Harel N, Lee SP, Nagaoka T, Kim DS, Kim SG (2002) Origin of negative blood oxygenation level-dependent fMRI signals. J Cereb Blood Flow Metab 22:908-917.

Hermán P, Trübel HK, Hyder F (2006) A multiparametric assessment of oxygen efflux from the brain. J Cereb Blood Flow Metab 26:79-91.

Horton RW, Meldrum BS, Pedley TA, McWilliam JR (1980) Regional cerebral blood flow in the rat during prolonged seizure activity. Brain Res 192:399-412.

Hoshi Y, Tamura M (1992) Cerebral oxygenation state in chemically- 
induced seizures in the rat-study by near infrared spectrophotometry. Adv Exp Med Biol 316:137-142.

Huppert TJ, Allen MS, Benav H, Jones PB, Boas DA (2007) A multicompartment vascular model for inferring baseline and functional changes in cerebral oxygen metabolism and arterial dilation. J Cereb Blood Flow Metab 27:1262-1279.

Iadecola C, Yang G, Ebner TJ, Chen G (1997) Local and propagated vascular responses evoked by focal synaptic activity in cerebellar cortex. J Neurophysiol 78:651-659.

Ingvar M (1986) Cerebral blood flow and metabolic rate during seizures. Relationship to epileptic brain damage. Ann N Y Acad Sci 462:194-206.

Kreisman NR, Magee JC, Brizzee BL (1991) Relative hypoperfusion in rat cerebral cortex during recurrent seizures. J Cereb Blood Flow Metab 11:77-87.

Lassen NA (1964) Autoregulation of cerebral blood flow. Circ Res 15 [Suppl]: 201-204.

Logothetis NK, Wandell BA (2004) Interpreting the BOLD signal. Annu Rev Physiol 66:735-769.

Martin C, Martindale J, Berwick J, Mayhew J (2006) Investigating neuralhemodynamic coupling and the hemodynamic response function in the awake rat. Neuroimage 32:33-48.

Martin RM, Halsey JH Jr (1983) Local PO2 and unit activity measured with an oxygen microelectrode from the gerbil cerebral cortex during seizure and EEG suppression. Adv Exp Med Biol 159:175-180.

Masamoto K, Omura T, Takizawa N, Kobayashi H, Katura T, Maki A, Kawaguchi H, Tanishita K (2003) Biphasic changes in tissue partial pressure of oxygen closely related to localized neural activity in guinea pig auditory cortex. J Cereb Blood Flow Metab 23:1075-1084.

Meldrum BS (2002) Concept of activity-induced cell death in epilepsy: historical and contemporary perspectives. Prog Brain Res 135:3-11.

Meldrum BS, Nilsson B (1976) Cerebral blood flow and metabolic rate early and late in prolonged epileptic seizures induced in rats by bicuculline. Brain 99:523-542.

Mulligan SJ, MacVicar BA (2004) Calcium transients in astrocyte endfeet cause cerebrovascular constrictions. Nature 431:195-199.

Nemoto M, Sheth S, Guiou M, Pouratian N, Chen JWY, Toga AW (2004) Functional signal and paradigm-dependent linear relationships between synaptic activity and hemodynamic responses in rat somatosensory cortex. J Neurosci 24:3850-3861.

Nersesyan H, Hyder F, Rothman DL, Blumenfeld H (2004a) Dynamic fMRI and EEG recordings during spike-wave seizures and generalized tonicclonic seizures in WAG/Rij rats. J Cereb Blood Flow Metab 24:589-599.

Nersesyan H, Herman P, Erdogan E, Hyder F, Blumenfeld H (2004b) Relative changes in cerebral blood flow and neuronal activity in local microdomains during generalized seizures. J Cereb Blood Flow Metab 24:1057-1068.

Offenhauser N, Thomsen K, Caesar K, Lauritzen M (2005) Activity-induced tissue oxygenation changes in rat cerebellar cortex: interplay of postsynaptic activation and blood flow. J Physiol 565:279-294.

Penfield W, Von Santha K, Capriani A (1939) Cerebral blood flow during induced epileptifom seizures in animals and man. J Neurophysiol 2:257-267.

Peppiatt CM, Howarth C, Mobbs P, Attwell D (2006) Bidirectional control of CNS capillary diameter by pericytes. Nature 443:700-704.

Pinard E, Rigaud AS, Riche D, Naquet R, Seylaz J (1987) Continuous determination of the cerebrovascular changes induced by bicuculline and kainic acid in unanaesthetized spontaneously breathing rats. Neuroscience 23:943-952.

Plum F, Posner JB, Troy B (1968) Cerebral metabolic and circulatory responses to induced convusions in animals. Arch Neurol 18:1-13.
Prince DA, Wilder BJ (1967) Control mechanisms in cortical epileptogenic foci. "Surround" inhibition. Arch Neurol 16:194-202.

Quan L, Sobey CG (2000) Selective effects of subarachnoid hemorrhage on cerebral vascular responses to 4-aminopyridine in rats. Stroke 31:2460-2465.

Raichle ME, Mintun MA (2006) Brain work and brain imaging. Annu Rev Neurosci 29:449-476.

Sato C, Nemoto M, Tamura M (2002) Reassessment of activity-related optical signals in somatosensory cortex by an algorithm with wavelengthdependent path length. Jpn J Physiol 52:301-312.

Schwartz TH, Bonhoeffer T (2001) In vivo optical mapping of epileptic foci and surround inhibition in ferret cerebral cortex. Nat Med 7:1063-1067.

Sheth S, Nemoto M, Guiuo M, Walker M, Pouratian N, Toga AW (2003) Evaluation of coupling between optical intrinsic signals and neuronal activity in rat somatosensory cortex. Neuroimage 19:884-894.

Sheth SA, Nemoto M, Guiou M, Walker M, Pouratian N, Toga AW (2004a) Linear and nonlinear relationships between neuronal activity, oxygen metabolism, and hemodynamic response. Neuron 42:347-355.

Sheth SA, Nemoto M, Guiou M, Walker M, Pouratian N, Hageman N, Toga AW (2004b) Columnar specificity of microvascular oxygenation and volume responses: implications for functional brain mapping. J Neurosci 24:634-641.

Shmuel A, Augath M, Oeltermann A, Logothetis NK (2006) Negative functional MRI response correlates with decreases in neuronal activity in monkey visual area V1. Nat Neurosci 9:569-577.

Simon RP (1985) Physiologic consequences of status epilepticus. Epilepsia 26 [Suppl 1]:S58-S66.

Skarphedinsson J, Harding H, Thoren P (1983) Repeated measurements of cerebral blood flow in rats. Comparison between hydrogen clearance method and laser Doppler flowmetry. Acta Physiol Scand 134:133-142.

Sobey CG, Faraci FM (1999) Inhibitory effect of 4-aminopyridine on responses of the basilar artery to nitric oxide. $\mathrm{Br} \mathrm{J}$ Pharmacol 126:1437-1443.

Suh M, Bahar S, Mehta AD, Schwartz TH (2005) Temporal dependence in uncoupling of blood volume and oxygenation during interictal epileptiform events in rat neocortex. J Neurosci 25:68-77.

Takano T, Tian GF, Peng W, Lou N, Libionka W, Han X, Nedergaard M (2006) Astrocyte-mediated control of cerebral blood flow. Nat Neurosci 9:260-267.

Thompson JK, Peterson MR, Freeman RD (2003) Single-neuron activity and tissue oxygenation in the cerebral cortex. Science 299:1070-1072.

Trevelyan AJ, Sussillo D, Watson BO, Yuste R (2006) Modular propagation of epileptiform activity: evidence for an inhibitory veto in neocortex. J Neurosci 26:12447-12455.

Weinand ME, Carter LP, Patton DD, Oommen KJ, Labiner DM, Talwar D (1994) Long-term surface cortical cerebral blood flow monitoring in temporal lobe epilepsy. Neurosurgery 35:657-664.

Winship IR, Plaa N, Murphy TH (2007) Rapid astrocyte calcium signals correlate with neuronal activity and onset of the hemodynamic response in vivo. J Neurosci 27:6268-6272.

Woolsey TA, Rovainene CM, Cox SB, Henegar MH, Liang GE, Liu D, Moskalento YE, Sui J, Wei L (1996) Neuronal units linked to microvascular modules in cerebral cortex: reponse elements for imaging the brain. Cereb Cortex 6:647-660.

Zhao M, Suh M, Ma H, Perry C, Geneslaw A, Schwartz TH (2007) Focal increases in perfusion and decreases in hemoglobin oxygenation precede seizure onset in spontaneous human epilepsy. Epilepsia 48:2059-2067.

Zheng Y, Johnston D, Berwick J, Chen D, Billings S, Mayhew J (2005) A three-compartment model of the hemodynamic response and oxygen delivery to brain. Neuroimage 28:925-939. 